\title{
Cure Characterization of Triglycidyl Epoxy/Aromatic Amine Systems
}

\author{
A. PADMA, ${ }^{1}$ R. M. V. G. K. RAO, ${ }^{1, *}$ C. SUBRAMANIAM, ${ }^{1}$ and G. NAGENDRAPPA ${ }^{2}$ \\ 'F.R.P. Pilot Plant, Materials Science Division, National Aerospace Laboratories, Bangalore, 17, India; \\ ${ }^{2}$ Department of Chemistry, Bangalore University, Bangalore, India
}

\begin{abstract}
SYNOPSIS
The curing of triglycidyl para-aminophenol (TGPAP) epoxy resin with three aromatic amine hardeners, diaminodiphenye sulphone (DDS), pyridinediamine (PDA), and toluenediamine (TDA), has been investigated. A series of isothermal cures was conducted and analyzed by Fourier transform infrared spectrometry (FTIR) and differential scanning calorimetry (DSC). The chemical reactions occurring during cure were monitored at different temperatures by qualitative and quantitative estimation of different groups in the IR spectra, and the ratio of rate constants $\left(k_{2} / k_{1}\right)$ were evaluated. Dynamic DSC analysis of TGPAP/ TDA resulted in two exothermal peaks, indicating cure kinetics different from those of TGPAP/DDS and TGPAP/PDA systems, which gave a single exothermal peak. Various kinetic parameters such as total heat of reaction $\Delta H^{\prime}$, activation energy $E_{a}$, Frequency factor $z$, and order of reaction $n$ were evaluated for all the three systems. From the initial kick-off temperatures and activation energy values it was concluded that the rate of curing followed the order TDA > PDA > DDS. The reaction conversions during cure, evaluated from IR analysis, were exactly the same as those obtained from DSC Borchardt-Daniels kinetics. Using this model, the plots of time vs. temperature for different conversions were constructed for all the three systems; on the basis of these, the cure cycles can be fixed. (c) 1995 John Wiley \& Sons, Inc.
\end{abstract}

\section{INTRODUCTION}

Linear epoxy resins are converted into three-dimensional thermoset networks by different chemical reactions. The mechanism followed by these reactions dictates the processing conditions and influences the network morphology. Among many techniques available, FTIR and DSC are valuable for investigating the cure reaction kinetics. The evaluation of kinetic parameters of the epoxy/amine reactions by $\mathrm{IR}^{1-3}$ and $\mathrm{DSC}^{4-10}$ analysis is well documented. The curing of triglycidyl epoxy resin (TGPAP) with diaminodiphenylmethane and a novel polyamine, using a DSC technique, was reported in our earlier publication. ${ }^{10}$ In the present study, the cure reactions of TGPAP resin with diaminodiphenylsulphone (DDS), pyridinediamine

\footnotetext{
* To whom correspondence should be addressed. Journal of Applied Polymer Science, Vol. 57, 401-411 (1995) (c) 1995 John Wiley \& Sons, Inc. CCC 0021-8995/95/040401-11
}

(PDA), and toluenediamine (TDA) hardeners were investigated using IR and DSC methods. TGPAP was used as the resin system because of its extensive use as a matrix material in high-performance carbon fiber composites.

\section{EXPERIMENTAL}

\section{Materials}

The triglycidyl para-amino phenol (TGPAP) was synthesized in the laboratory with an epoxy equivalent weight (EEW) of $115 \mathrm{~g}$. The three hardeners used were: (1) 4,4'-diaminodiphenyl sulphone (DDS) $97 \%$ (Merck-Schuchardt), (2) 2,6-pyridinediamine (PDA) 97\% (Merck-Schuchardt), and (3) 3,4-toluenediamine (TDA) $98 \%$ pure (Fluka AG).

The chemical structures of the hardeners are given in Figure 1. 


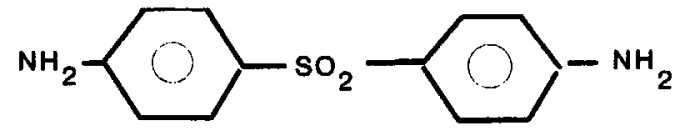

Diamino diphenyl sulphone (DDS)<smiles>Nc1cccc(N)n1</smiles>

Pyridinediamine(PDA)<smiles>Cc1ccc(N)c(N)c1</smiles>

Toluenediamine (TDA)

Figure 1 Structure of hardeners.

\section{Technique}

Stoichiometric ratios of epoxide and amine were used in all the three systems. The resin and finely powdered hardners were mixed using an ultrasonic mixer. The mixtures were degassed and kept in a desiccator at $0^{\circ} \mathrm{C}$.

The IR spectra at different intervals of time were obtained on a Bruker IFS-48 Fourier Transform infrared spectrometer at constant temperatures in the range of $100-180^{\circ} \mathrm{C}$. The sample was sandwiched between two $\mathrm{KBr}$ pellets and the spectra were averaged over 32 scans at a resolution of 4 . The fractional conversions of epoxide, primary amine, secondary amine, and hydroxyl groups around 908 $\mathrm{cm}^{-1}, 1620 \mathrm{~cm}^{-1}, 3348 \mathrm{~cm}^{-1}$ and $3500 \mathrm{~cm}^{-1}$, respectively, were calculated using alkyl absorption around $2923 \mathrm{~cm}^{-1}$ as a reference.

The calorimetric measurements were made with a TA instrument DSC 910 Differential Scanning Calorimeter, calibrated with high purity indium. The samples were weighed on a Sartorius balance corrected up to $0.0001 \mathrm{~g}$. Hermetically sealed cups were used to hold the samples. The thermograms were obtained at programmed heating rates of 10,15 , and $20^{\circ} \mathrm{C} / \mathrm{min}$, with a continuous nitrogen purge.

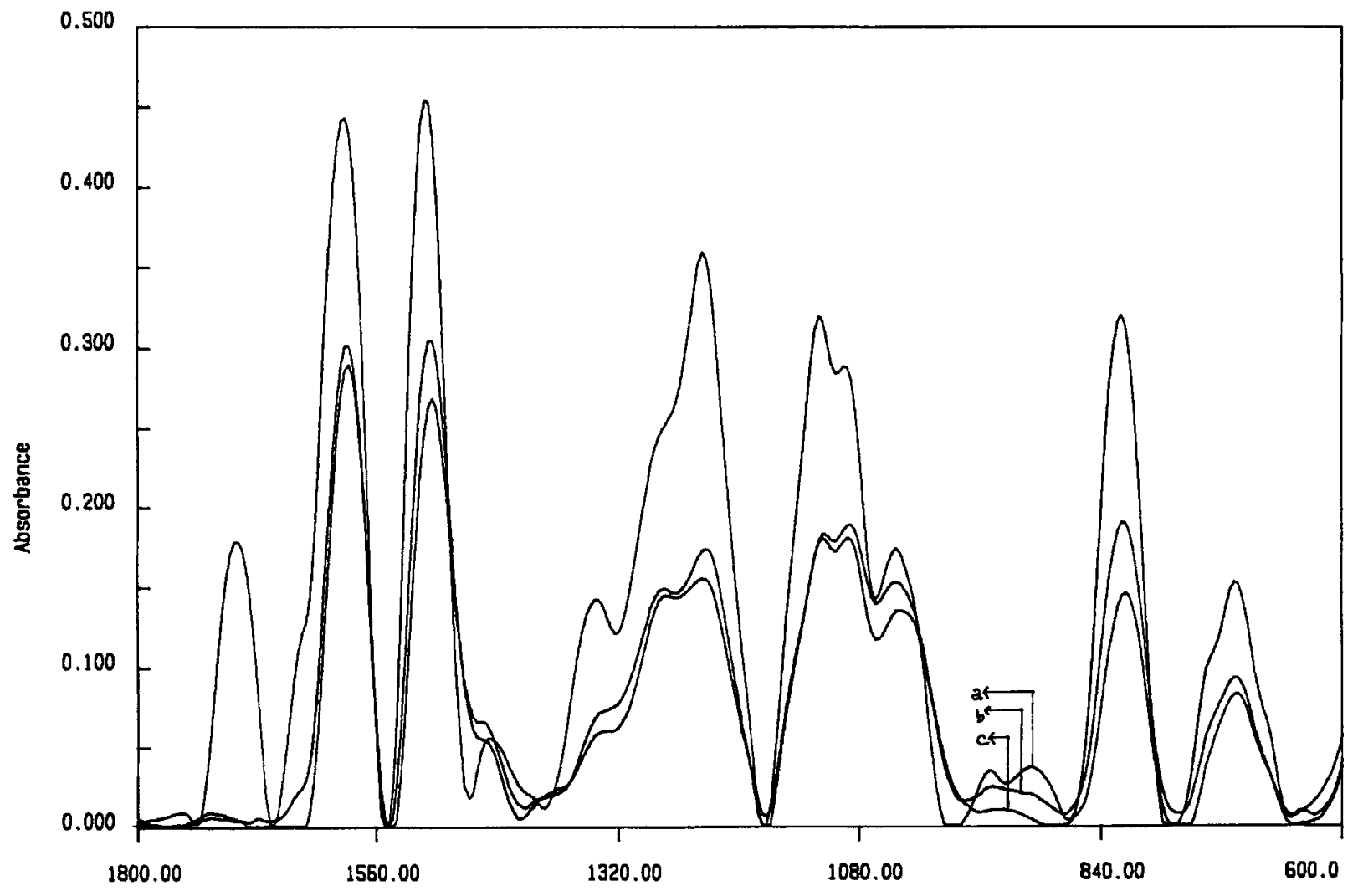

Figure 2 IR spectra of TGPAP/DDS at different intervals of time at $150^{\circ} \mathrm{C}$. 


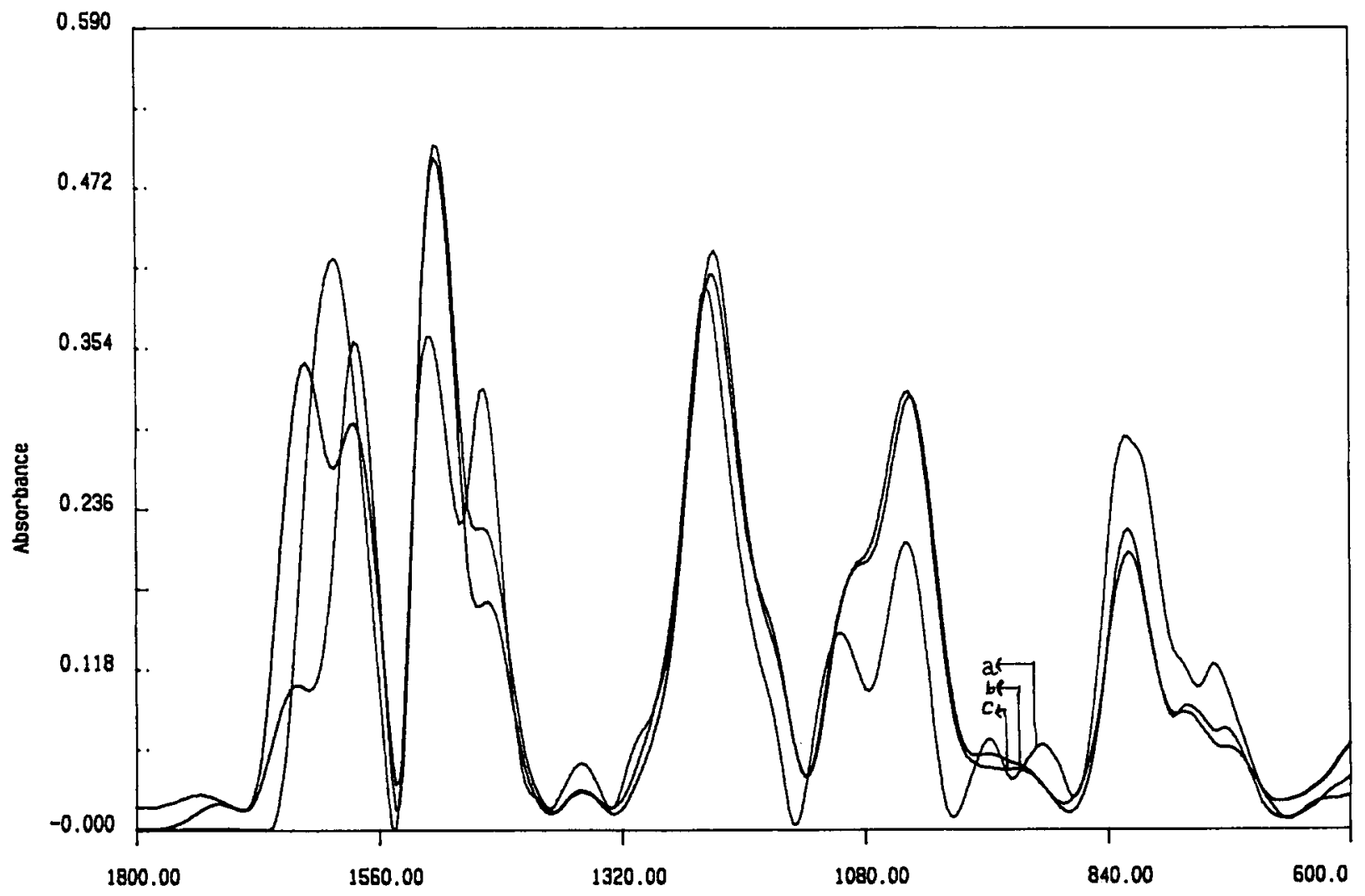

Figure 3 IR spectra of TGPAP/PDA at different intervals of time at $150^{\circ} \mathrm{C}$.

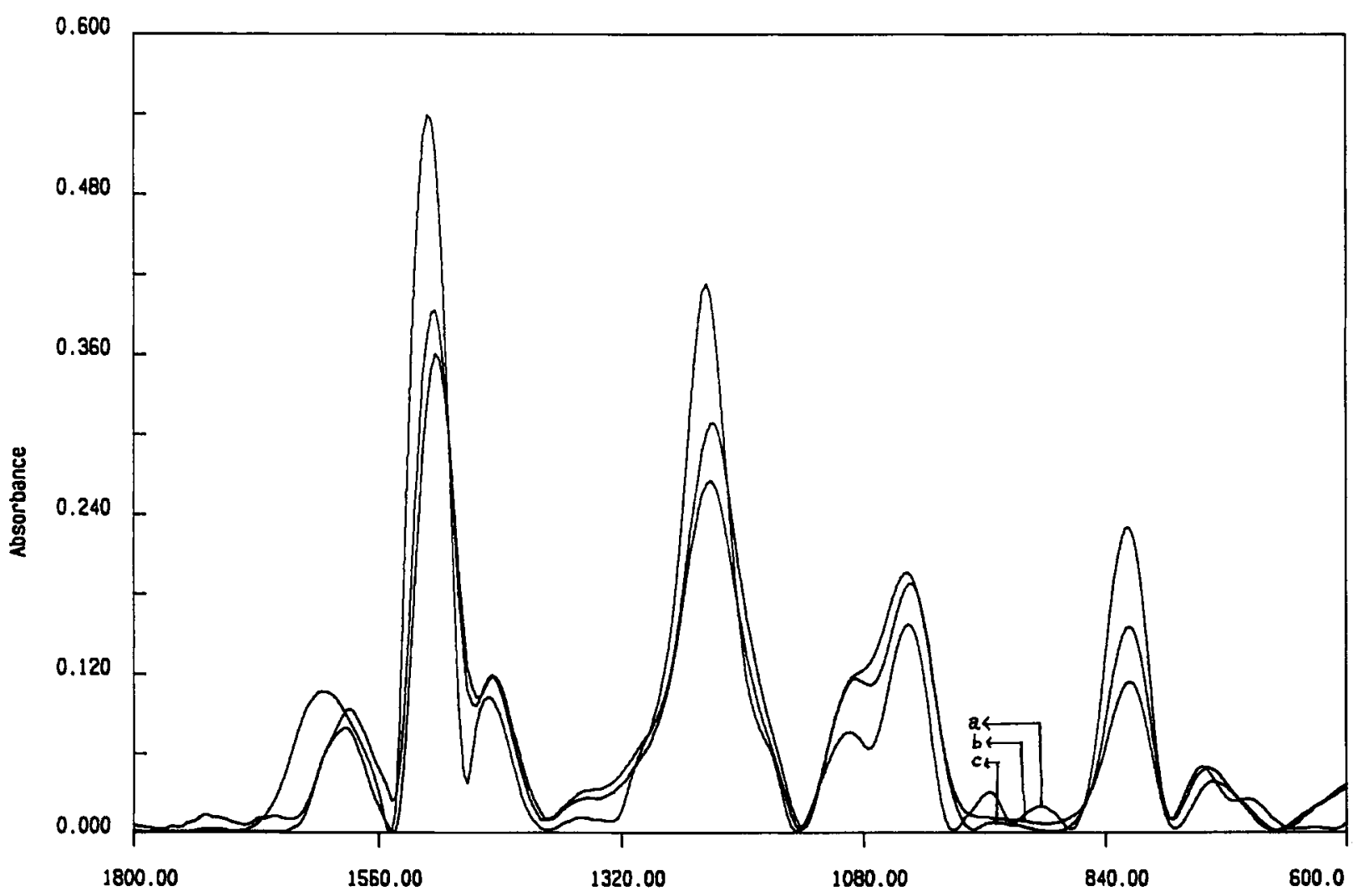

Figure 4 IR spectra of TGPAP/TDA at different intervals of time at $150^{\circ} \mathrm{C}$. 


$$
\mathrm{R}^{3}-\mathrm{NH}_{2}+\mathrm{R}-\mathrm{CH}^{-\mathrm{O}}-\mathrm{CH}_{2} \longrightarrow \mathrm{R}-\mathrm{CH}_{\mathrm{H}}^{\mathrm{OH}}-\mathrm{CH}_{2} \mathrm{NH} \mathrm{R}^{\prime}
$$<smiles>OCCNCCCOCCNNCCO</smiles>

$$
\mathrm{B}-\mathrm{CH}-\mathrm{CH}_{2} \stackrel{\mathrm{Catalyst}}{\longrightarrow}\left(\mathrm{CH} \mathrm{R}-\mathrm{CH}_{2}-\mathrm{O}-+_{\mathrm{n}}-\right.
$$

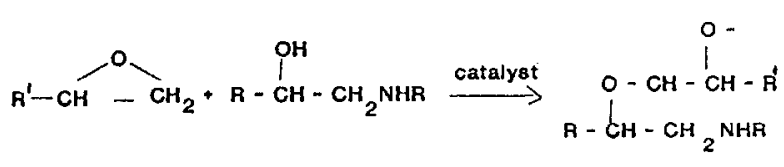

Figure 5 Epoxy amine reaction scheme.

\section{RESULTS AND DISCUSSIONS}

Figures 2, 3, and 4 represent the FTIR spectra of the TGPAP resin blended with DDS, PDA, and TDA, respectively, at different intervals of time at $150^{\circ} \mathrm{C}$. The spectra were zoomed in the $800-1800$ $\mathrm{cm}^{-1}$ region to show the epoxy and primary amine peaks clearly. The conversions of a functional groups with time were calculated using the equation

$$
(1-p)=\frac{I_{(t)} \times I_{(0) \text { standard }}}{I_{(0)} \times I_{(t) \text { standard }}}
$$

where $I=$ absorbance, subscript $(t)$ and $(0)$ refer to time $t$ and initial time, subscript standard refers to the internal standard $\left(2923 \mathrm{~cm}^{-1}\right.$ peak $) ; p=$ fractional conversion of the function group.

The reactions that usually occur in epoxy resins with the amines are as shown in Figure 5. From the

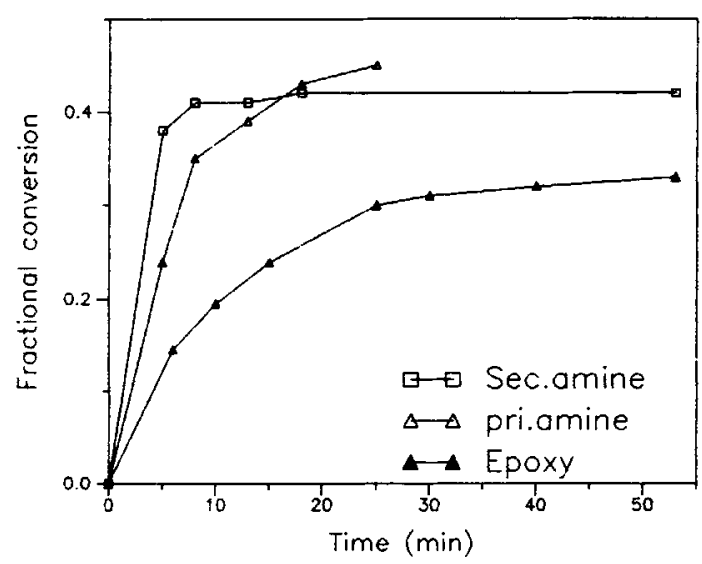

Figure 6 Fractional conversions vs. time in different groups in a TGPAP/DDS system at $150^{\circ} \mathrm{C}$.

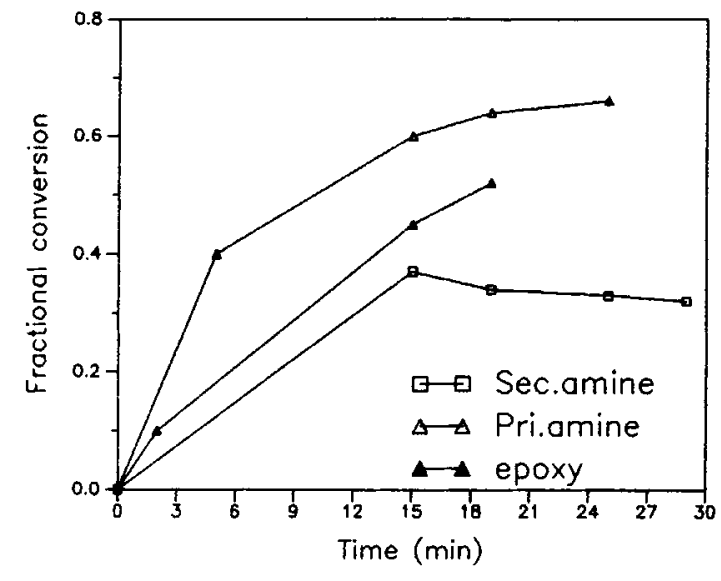

Figure 7 Fractional conversion vs. time in different groups in a TGPAP/PDA system at $150^{\circ} \mathrm{C}$.

IR spectral analysis the following observations were made. A sharp decrease in both epoxy and $\mathrm{NH}_{2}$ group concentrations at all the temperatures shows that the primary amine-epoxy reaction is the predominant cure reaction in the earlier stage of cure. During the later stages of cure the unreacted groups (both the primary and secondary amine) become inaccessible to epoxide groups because of network topography constraints. The fractional conversion vs. time plots (Figs. 6, 7, and 8) indicate that the TGPAP/DDS and TGPAP/PDA systems follow similar kinetics but that the kinetics of TGPAP/ TDA were different.

In TGPAP/DDS and TGPAP/PDA systems, (a) At lower temperature $\left(135^{\circ} \mathrm{C}\right)$ throughout the reaction the epoxy groups were consumed by primary amine hydrogen atoms. Secondary amine reaction was negligible, as indicated by the increase in intensity of the secondary amine peaks. Hydroxyl

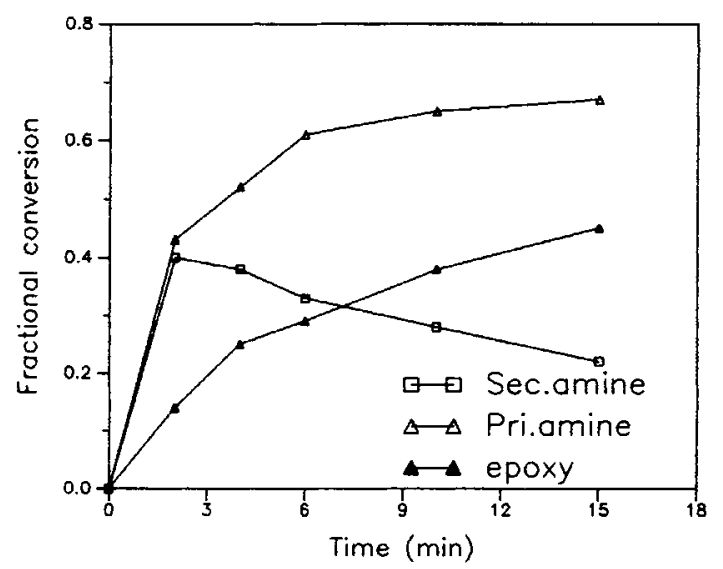

Figure 8 Fractional conversion vs. time in different groups in a TGPAP/TDA system at $150^{\circ} \mathrm{C}$. 


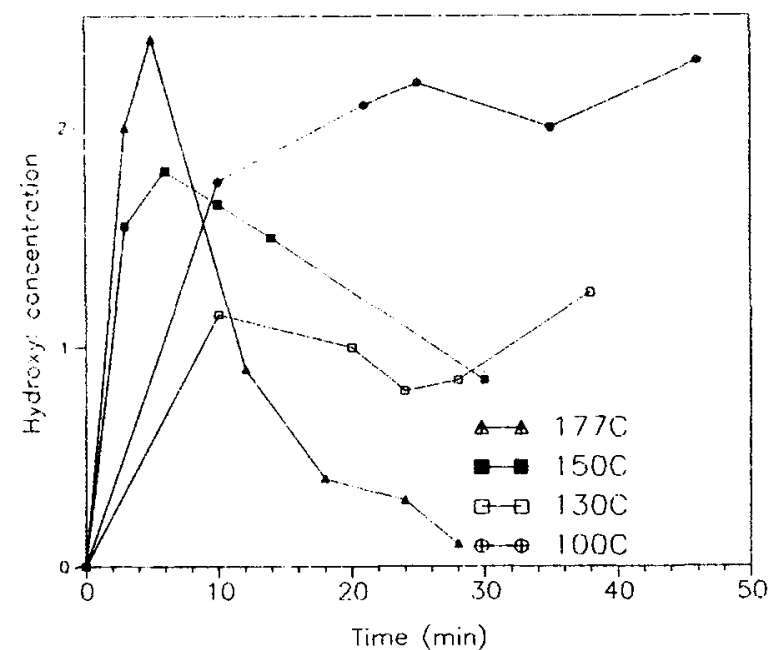

Figure 9 Changes in concentration of the hydroxyl group with time at different temperatures in a TGPAP/ TDA system.

group intensity also increased with time. (b) At $150^{\circ} \mathrm{C}$ in the earlier stages of reaction, both primary and secondary amine hydrogen atoms reacted with epoxy groups; later, reaction of primary amine hydrogen was predominent, as shown by the increase in secondary amine intensity. (c) At a higher temperature $\left(177^{\circ} \mathrm{C}\right)$ the reaction of both the primary amine and secondary amine was also initially simultaneous, but as the reaction proceeded further,

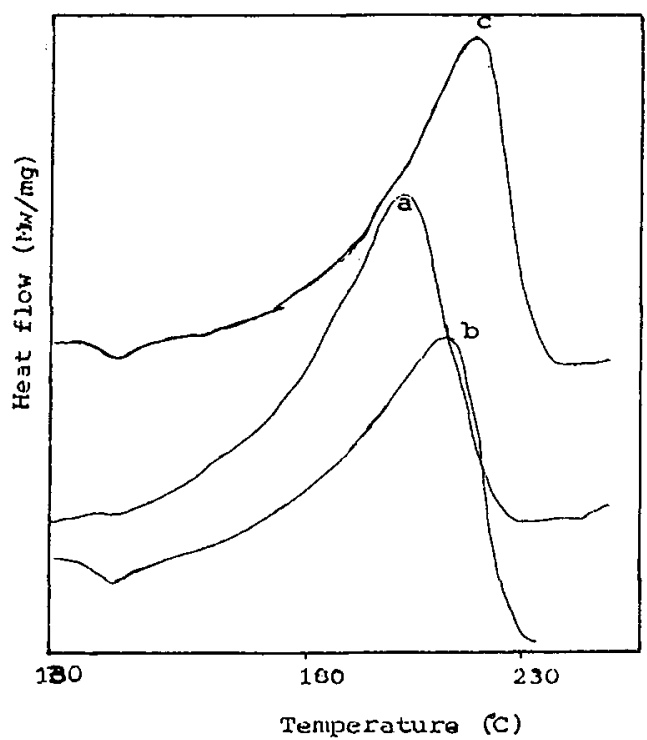

Figure 11 Dynamic DSC thermograms of TGPAP/ DDS at different heating rates.

only the primary amine reacted and the secondary amine ceased to react, as shown by an increase in the secondary amine concentration.

The hydroxyl group intensity increased first and then a slight decrease was observed, indicating epoxy-hydroxy etherification reaction [Fig. 5(d)].

In the TGPAP / TDA system the primary amine and epoxy also reacted early in the reaction, and the
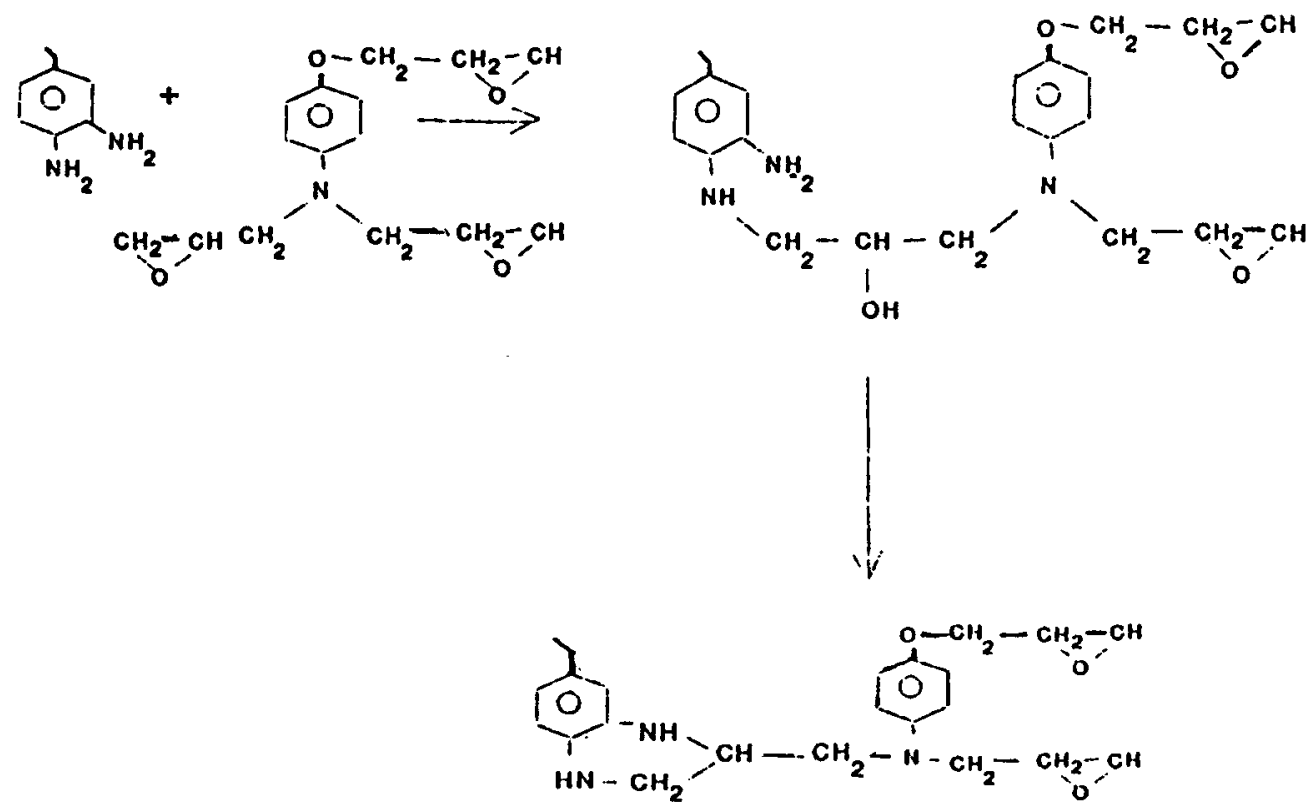

Figure 10 Possible intramolecular ring formation in a TGPAP/TDA system. 


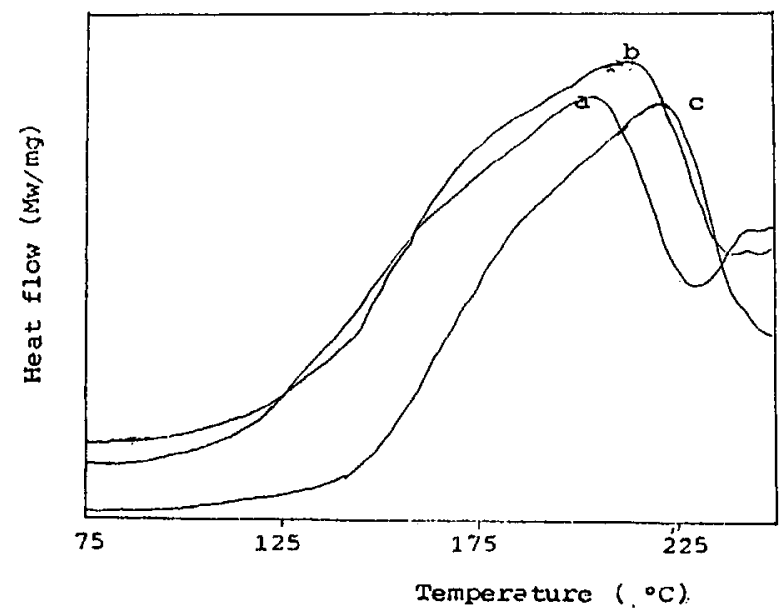

Figure 12 Dynamic DSC thermograms of TGPAP/ PDA at different heating rates.

reaction was highest at a higher temperature. But the unique behavior found in this system was that of the hydroxyl group: at higher temperatures (Fig. 9) a very prominent decrease in concentration of hydroxyl group was found at $177^{\circ} \mathrm{C}$. This may be because of a higher degree of epoxy-hydroxy etherification reaction compared to the secondary amine-epoxy reaction. Besides this, as the two $\mathrm{NH}_{2}$ groups are closely placed in the 3,4 position, intramolecular ring formation with the hydroxyl, as shown in Figure 10, is also possible. The presence of hydroxyl groups (autocatalytic) and the absence of free epoxy groups in the vicinity of the amines (due to viscosity constraints) may result in this ring formation. Further study is required to confirm the formation of a ring and evolution of water molecules during the reaction.

As the crosslinking increases, the mobility of both a primary and secondary amine is restricted. This behavior is common to all cases, but with TDA, the reactivity of the secondary amine is much reduced. This may be because of the very high reactivity of the primary amine hydrogen compared to the secondary amine hydrogen atoms. This might have resulted in the additional peak in DSC around $170^{\circ} \mathrm{C}$.

Using the fractional conversions of each group obtained from IR, the kinetic ratio was calculated. The kinetic ratio $K$, is the ratio of the rate constant for the secondary amine-epoxy reaction $k_{2}$ to the rate constant for the primary amine-epoxy reaction $k_{1}$, generally reported to be in the range of 0.1 to 1 . For equal reactivity of amine hydrogen atoms, $k_{2}$ / $k_{1}$ is 0.5 . The ratio is predicted to have an influence on the chemical and physical properties of the curing systems, because the reaction of secondary amine with epoxy is the principal factor for introducing

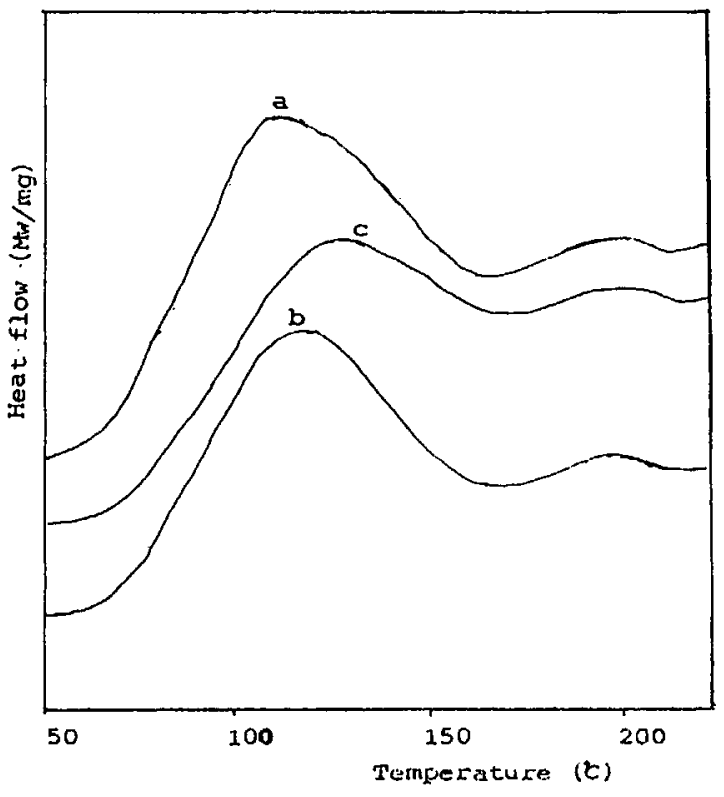

Figure 13 Dynamic DSC thermograms of TGPAP/ TDA at different heating rates.

branching points and crosslinking points into the developing molecular network.

Gillham et al. ${ }^{2}$ have given an equation for determining the $K$ value when $K$ is not equal to 1 .

$$
\begin{gathered}
\left.\left[1-\left(P_{A}-r_{B} P_{B}\right) / r_{B}\right)\right] /\left(1-P_{B}\right)=K /(K-1) \\
-1 / K-1(1-P)^{K} \text { when } K \neq 1 \\
P_{A}=\left([A]_{0}-[A]\right) /[A]_{0} ; \\
P_{B}=\left([B]_{0}-[B]\right) /[B]_{0} ;
\end{gathered}
$$

where $P_{A}$ and $P_{B}$ represent the fractional conversions of epoxide and primary amine respectively and $r_{B}$ is the ratio of concentrations of initial primary amine to epoxide groups.

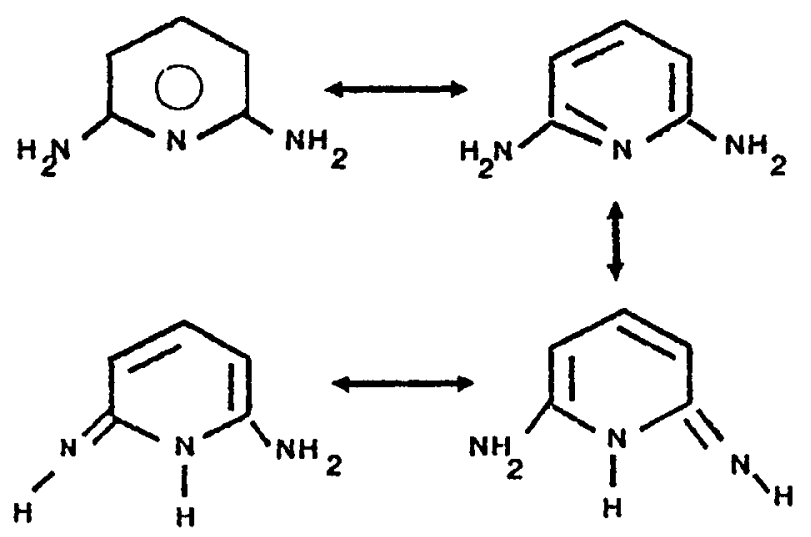

Figure 14 Resonance structures of Pyridinediamine. 


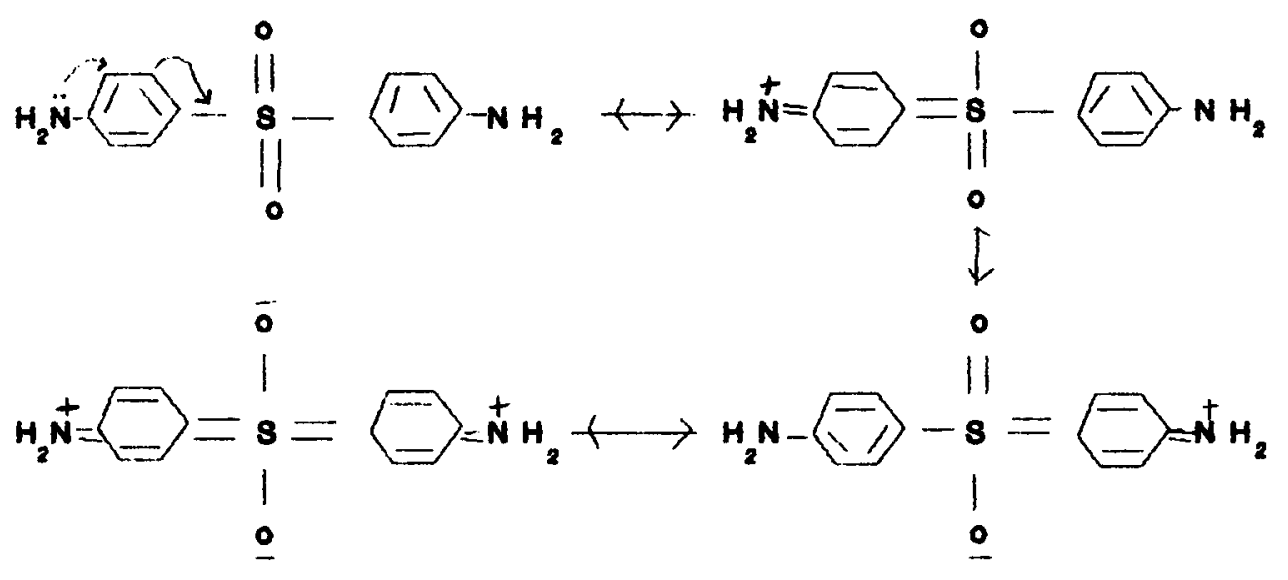

Figure 15 Resonance structures of Diaminodiphenyl sulphone.

$[A]_{0}$ and $[B]_{0}$ are the initial concentrations of the epoxide and primary amine group, respectively.

The $K$ values obtained using the above equation are 0.75 for TGPAP/PDA, 0.4 for TGPAP/DDS, and 0.31 for TGPAP/TDA systems, respectively at $150^{\circ} \mathrm{C}$.

From the dynamic DSC thermograms (Figs. 11, 12 , and 13), it was seen that TGPAP/DDS and TGPAP / PDA gave a single exothermal peak, and TGPAP/TDA gave two exothermal peaks in the temperature range $30-220^{\circ} \mathrm{C}$.

The reaction kickoff temperature was at a minimum with TDA and a maximum with DDS. This gives the reactivity order as TDA > PDA > DDS. This is in accordance with the structures of the amines. TDA is very basic in nature, as the reactivity of aniline will be enhanced by the electron-donating methyl group as well as the adjacent $\mathrm{NH}_{2}$ groups in the 3, 4 position. Though PDA has two $\mathrm{NH}_{2}$ groups, the charge on the amino nitrogen would be withdrawn by the pyridine ring nitrogen through reso-

Table I Cure Characteristics at Different Heating Rates

\begin{tabular}{ccccccc}
\hline & $\begin{array}{c}\text { Heating } \\
\text { Rate } \\
\text { System }\end{array}$ & $\begin{array}{c}T_{i} \\
(\mathrm{~K} / \mathrm{min})\end{array}$ & $\begin{array}{c}T_{p 1} \\
(\mathrm{~K})\end{array}$ & $\begin{array}{c}T_{p 2} \\
(\mathbf{K})\end{array}$ & $\begin{array}{c}T_{i} \\
(\mathrm{~K})\end{array}$ & $\begin{array}{c}\Delta H \\
(\mathrm{~J} / \mathrm{g})\end{array}$ \\
\hline \multirow{2}{*}{ TGPAP/DDS } & 10 & 416 & 482 & - & 505 & 348 \\
& 15 & 414 & 488 & - & 504 & 352 \\
& 20 & 412 & 495 & - & 510 & 368 \\
TGPAP/PDA & 10 & 378 & 478 & - & 485 & 339 \\
& 15 & 377 & 485 & - & 515 & 353 \\
TGPAP/TDA & 20 & 379 & 491 & - & 520 & 352 \\
& 10 & 331 & 380 & 458 & 476 & 280 \\
& 15 & 334 & 390 & 470 & 491 & 251 \\
& 20 & 331 & 402 & 474 & 493 & 262 \\
\hline
\end{tabular}

nance (Fig. 14). In DDS, the electron attracting aryl $-\mathrm{SO}_{2}$ - group reduces the reactivity (Fig. 15). Table I presents the initial kickoff temperature $\left(T_{i}\right)$, peak exothermal temperature $\left(T_{p}\right)$, and final temperature $\left(T_{f}\right)$ and total heat of reaction $(\Delta H)$. The kinetic parameters such as activation energy $\left(E_{a}\right)$ order of reaction $(n)$ and Arrhenius frequency factor $(z)$ were evaluated (Table II), using BorchardtDaniels Kinetics, assuming that the curing reaction obeys Arrhenius kinetics.

A simple and accurate relationship between the activation energy and peak exothermal temperature at different heating rates $\phi$, based on the work of Ozawa, ${ }^{11}$ Bascom and Peyser, ${ }^{12}$ was used to calculate the activation energy.

$$
E=\frac{-R \Delta \log \phi}{0.4567 \Delta\left(1 / T_{p}\right)}=\frac{-R \Delta \ln \phi}{1.052 \Delta\left(1 / T_{p}\right)}
$$

The plots of reaction $\%$ conversion vs. time for all the three systems were constructed. The epoxy conversions obtained from IR analysis were compared with those obtained from DSC. The conversions coincide exactly with the Borchardt-Daniels plots of reaction conversions vs. time at the given isothermal conditions. Figures 16, 17, and 18 represent the plots for DDS, PDA, and TDA systems,

Table II Kinetic Data Evaluated from DSC

\begin{tabular}{lccccc}
\hline & \multicolumn{2}{c}{$E_{a}(\mathrm{KJ} / \mathrm{mol})$} & & \\
\cline { 2 - 3 } Resin System & B.D & Ozawa & & & \multicolumn{1}{c}{$Z$} \\
\hline TGPAP/DDS & 110 & 115 & 2 & 11 \\
TGPAP/PDA & 95.5 & 94 & 2.4 & 10.47 \\
TGPAP/TDA & 57 & 55 & 4.4 & 11 \\
\hline
\end{tabular}




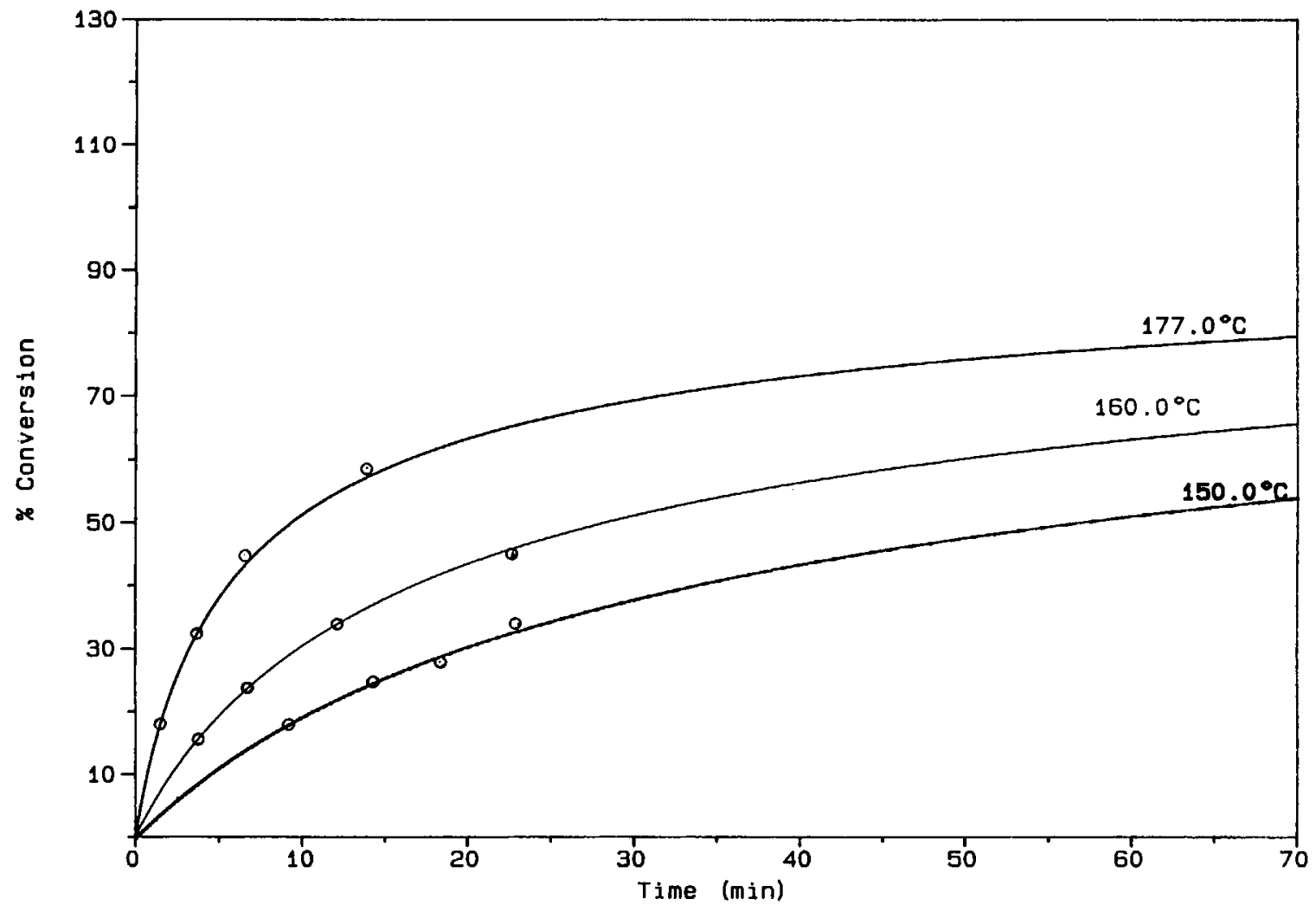

Figure 16 Conversion vs. time at different temperatures in TGPAP/DDS.

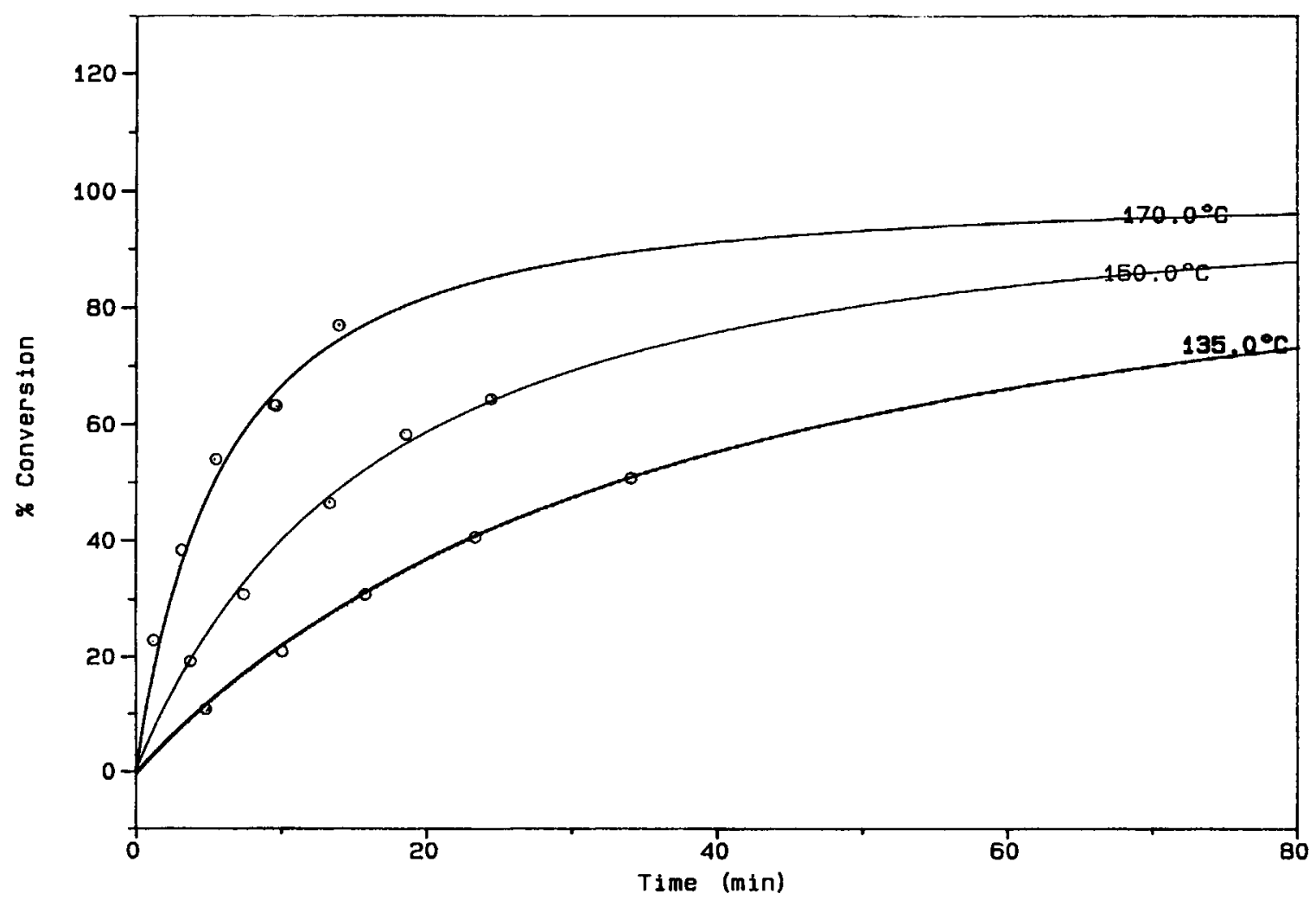

Figure 17 Conversion vs. time at different temperatures in TGPAP/PDA. 


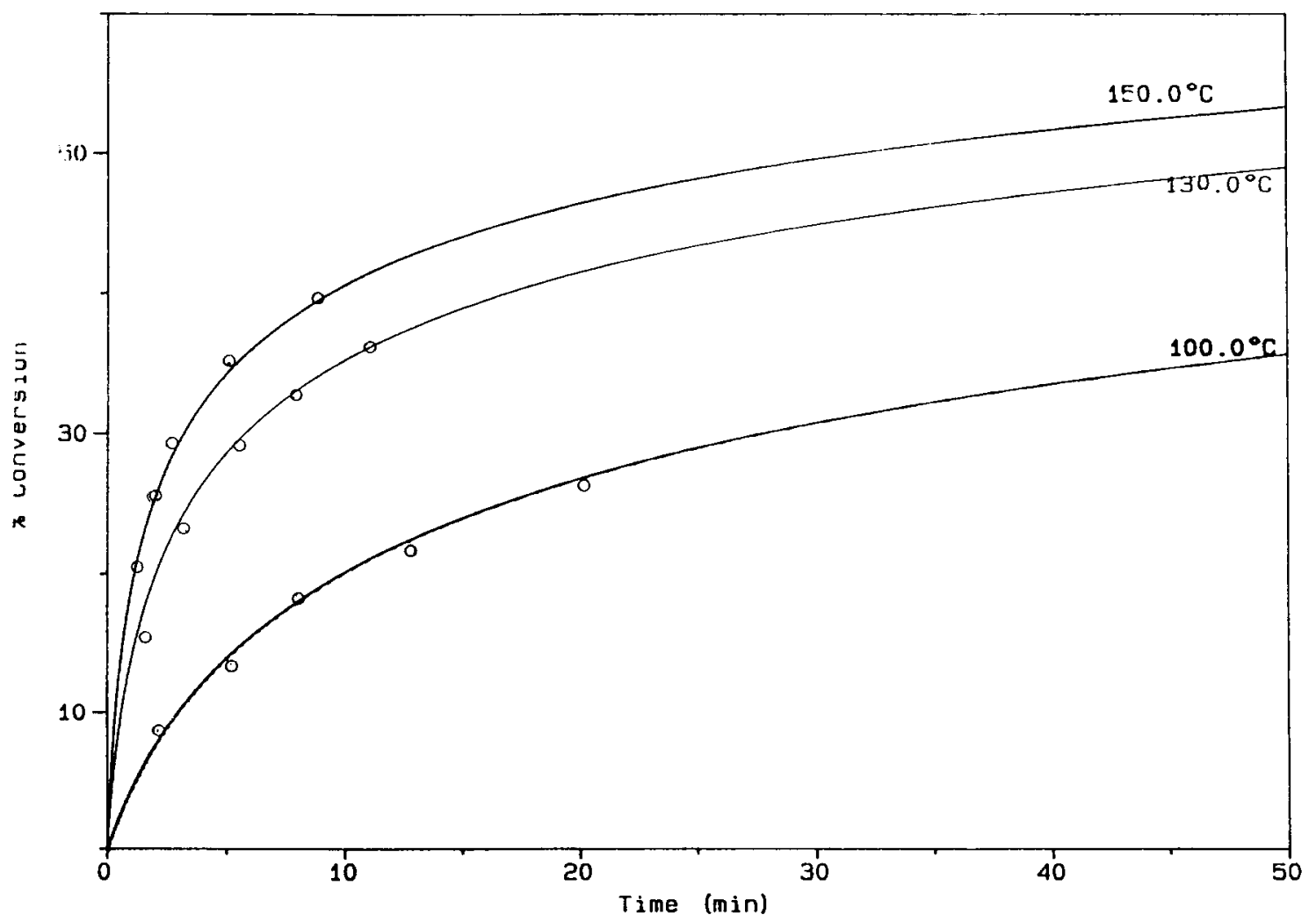

Figure 18 Conversion vs. time at different temperatures in TGPAP/TDA.

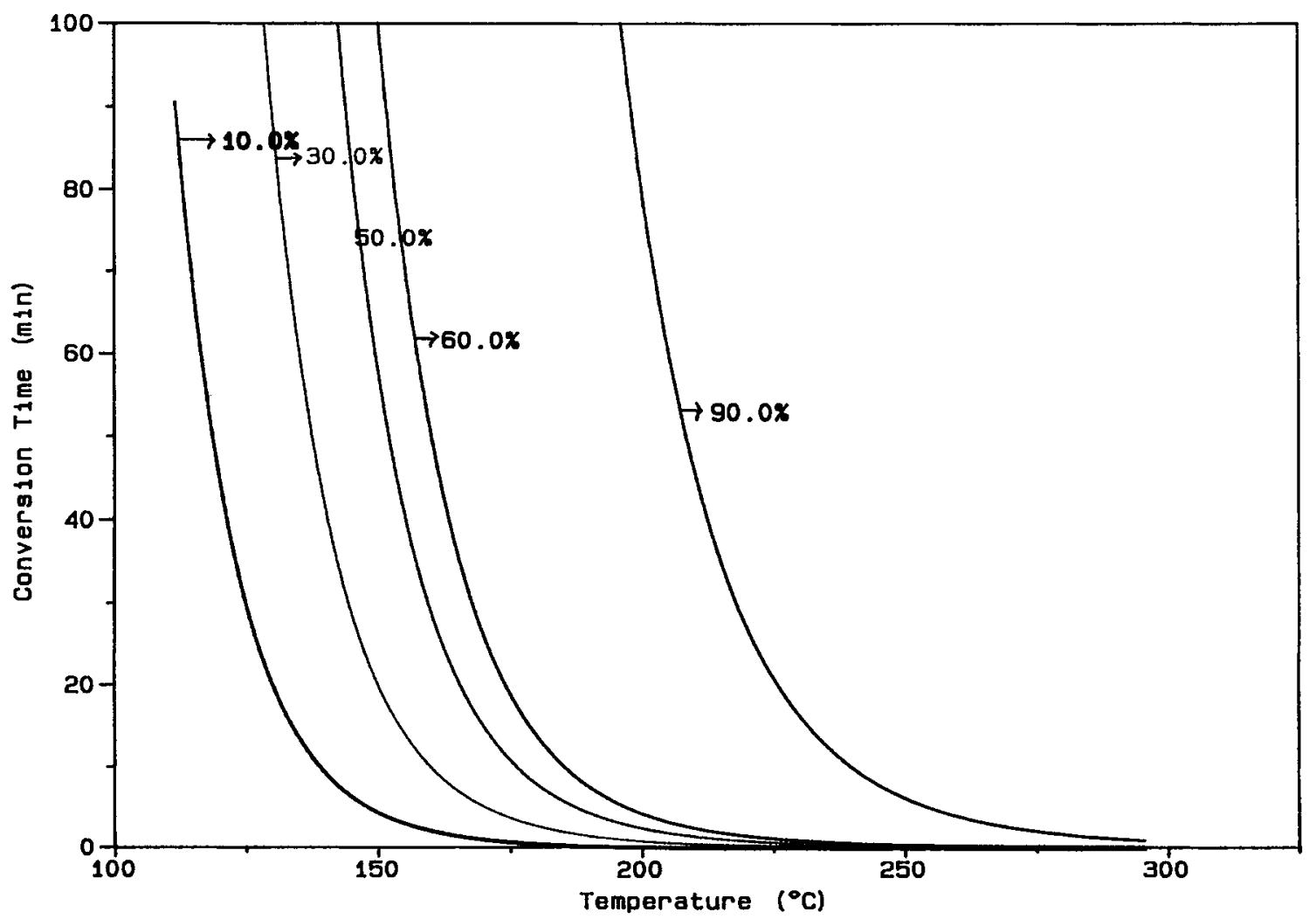

Figure 19 Conversion time vs. temperature at different \% conversions in TGPAP/DDS. 


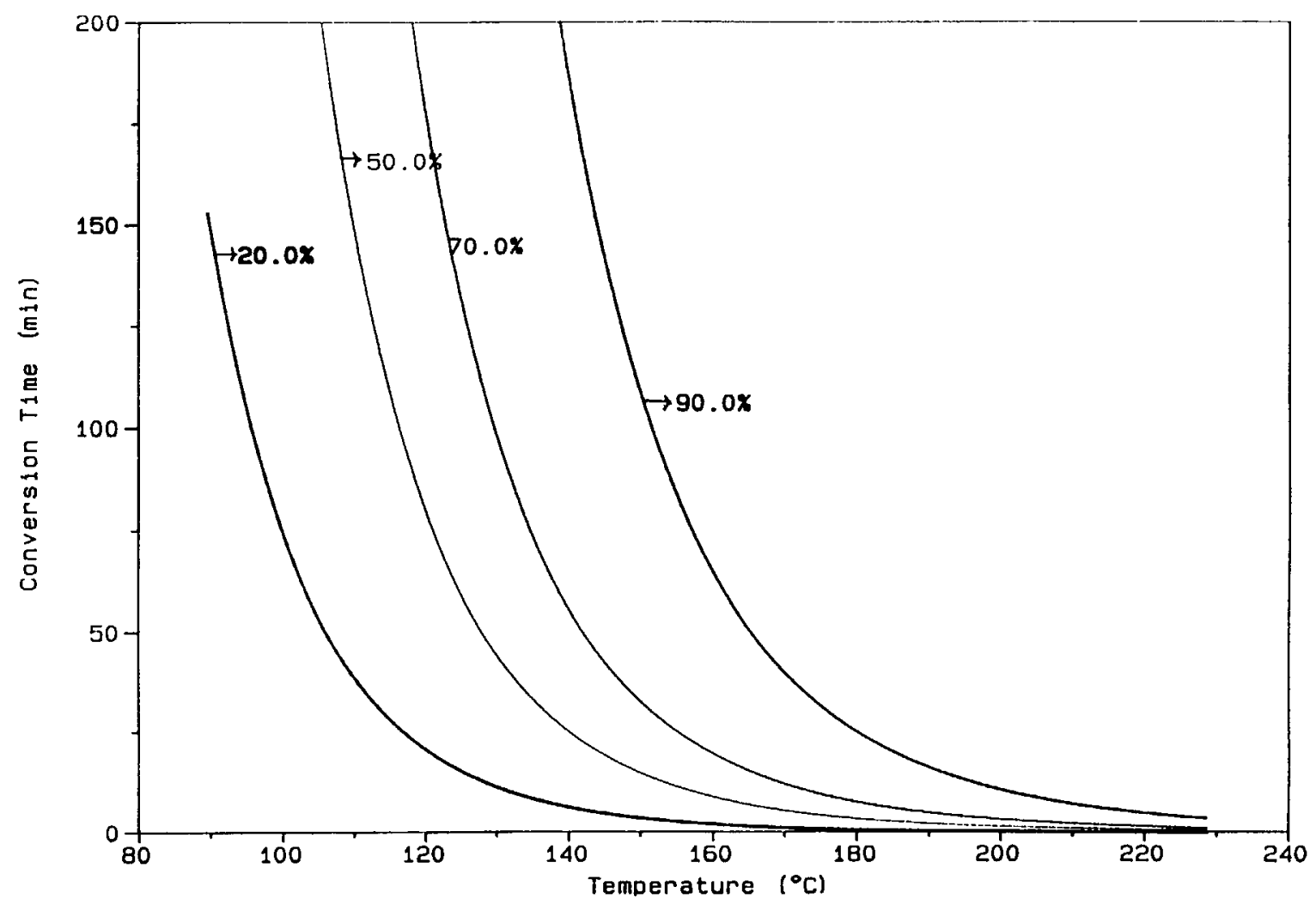

Figure 20 Conversion time vs. temperature at different $\%$ conversions in a TGPAP/ PDA system.

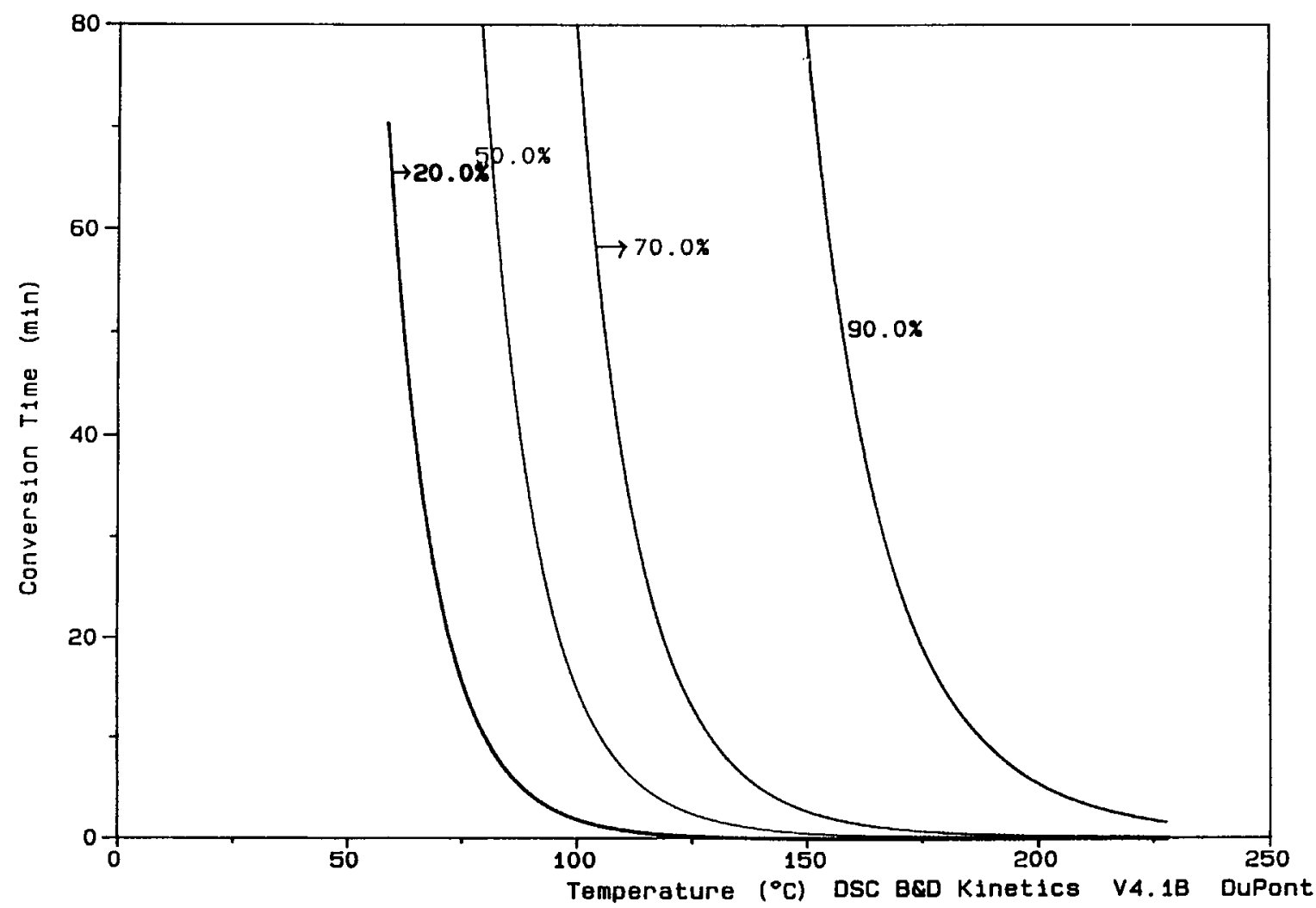

Figure 21 Conversion time vs. temperature at different $\%$ conversions in a TGPAP/ TDA system. 
respectively. Finally, plots of conversion time vs. temperature for different percentage cures were constructed for all the three systems (Figures 19, 20 , and 21). Using these plots, the cure cycles for the systems can be constructed.

\section{CONCLUSIONS}

The cure kinetics of TGPAP resin with three aromatic amine hardeners have been investigated using FTIR and DSC methods.

From the IR analysis, the plots of reaction conversion vs. time for all the systems were constructed. The kinetic ratios $K$ for all the systems were calculated. The kinetic parameters such as total heat of reaction, activation energy, frequency factor, and order of reaction, were determined using DSC analysis. From the data obtained, the order of reactivity of amines with TGPAP was found to be TDA > PDA $>$ DDS. The reaction conversions obtained from IR analysis coincide exactly with the conversions obtained from DSC Borchardt-Daniels plots of \% conversion vs. time. The plots of time vs. temperature for different conversions were constructed for all the three systems, which can form a basis to fix the cure cycles.

The authors are thankful to Dr. K. N. Raju, Director, and Prof. R. Narasimha, former Director, Dr. A. K. Singh,
Head, Materials Science Division of NAL for their support rendered in these studies.

\section{REFERENCES}

1. S. P. Abuin, M. P. Pellin, L. Nunez, J. S. Gandara, and P. P. Losada, J. Appl. Polym. Sci., 47, 533-541 (1993).

2. X. Wang and J. K. Gillham, J. Appl. Polym. Sci., 43, 2267-2277 (1991).

3. X. M. Zigon, M. Mukuz, T. Malavasic, and U. Ossedkar, J. Appl. Polym. Sci., Appl. Polym. Symp., 48, 481-492 (1991).

4. J. Mijovic, J. Appl. Polym. Sci., 31, 1177-1187 (1986).

5. R. J. Morgan and E. T. Mones, J. Appl. Polym. Sci., 33, 999-1020 (1987).

6. J. V. Duffy, E. Hui, and B. Hartmann, J. Appl. Polym. Sci., 33, 2959-2964 (1987).

7. R. D. Patel, R. G. Patel, and V. S. Patel, J. Therm. Anal., 34, 1283-1293 (1988).

8. K. S. Jagadeesh and Siddaramaiah, J. Appl. Polym. Sci., 43, 1459-1465 (1991).

9. K. S. Jagadeesh and Siddaramaiah, Polym. Int. (1991).

10. R. M. V. G. K. Rao, A. Padma, and H. S. Patel, High Perform. Polym., 4, 1 (1992).

11. T. Ozawa, J. Therm. Anal., 2, 301-324 (1970).

12. W. D. Bascom and P. Peyser, Anal. Calorim., 3, 537554 (1974).

Received October 24, 1994

Accepted December 5, 1994 